\title{
Automated transport in urban areas: opportunities in the Netherlands
}

\author{
J. H. Baggen \& E. M. L. Aben \\ Delft University of Technology, The Netherlands
}

\begin{abstract}
Automated transport could be one of the possibilities to contribute to the development of sustainable mobility in urban areas. In order to realize sustainable mobility in urban areas one should invest in collective and space efficient transport. With this purpose in mind, this paper is about nonmechanical guided automated transport on the road with the ambition to participate in conventional traffic in the long term, with the so-called cybernetic transport systems (CTS). As well as a contribution to sustainable mobility, these systems should also contribute to the current transport system: they have to answer (part of the) transportation demands. Since municipalities feel the direct consequences of conventional transport, they also feel the negative impacts of this kind of transport. The effects of these impacts make a municipality one of the most important stakeholders for the problems related to traffic in urban areas. This paper elaborates on the possibilities of CTS to contribute to the current transport system and on the possibilities of municipalities to develop innovative and sustainable transport systems like CTS.
\end{abstract}

Keywords: transport systems, transport policy, automated transport, sustainable mobility, urban planning.

\section{Introduction}

Ever since the last century mobility has constantly been growing. Expectations are that this will continue for a very long time. In its Mobility Report ("Nota Mobiliteit") the Dutch government states that mobility is all right ("mobiliteit mag"). Therefore, measures to be taken to deal with this dilemma focus on reducing the negative aspects of transportation. This way of dealing with the dilemma refers to the development of sustainable mobility. 
Automated transport is expected to be one of the solutions which can contribute to sustainable mobility. That is why research to develop automated systems is performed. This paper focuses on the development of so-called cybernetic transport systems (CTS).

\section{Cybernetic Transport Systems (CTS)}

Cybercars are road vehicles with fully automated driving capabilities. A fleet of such vehicles forms a transportation system for passengers or goods on a network of roads with on-demand and door-to-door capability. A central management system controls the fleet of cars in order to meet particular demands in a particular environment. In the initial stages cybercars are designed for short trips at low speed in an urban environment or on private grounds.

In the long term cybercars could also run autonomously at high speed on dedicated tracks. With the development of the cybercar infrastructures, private cars with fully autonomous driving capabilities could also be allowed on these infrastructures while maintaining their manual mode on standard roads.

Cybercars are members of the general family of people movers and closely related to PRT (Personal Rapid Transit) but they offer the advantage of being able to run on any ground infrastructure, which means that they are cheaper and more flexible [6].

\section{Problem analysis}

The development of automated transport systems, and thus CTS, is mostly technology driven. Experiments in this field are done in niches of the transport market. The goal of the development of these automated transport systems is to integrate into the existing transport system and, by doing so, to contribute to the development of sustainable mobility. Not only technical demands need to be met to accomplish this integration, but social issues have to be dealt with as well. Due to the fact that the development of CTS mainly took place in the niche of the transport market, little is known about the use of CTS in urban areas, and about the demands the transport systems have on the organizational setting.

By identifying and analyzing the contribution of a service by CTS to the transport services in urban areas and by identifying and analyzing the possibilities of a municipality to the development of a new transport system, this paper tries to define conditions for success and failure for the development of CTS in urban areas.

\section{Impact of conventional transport modes and CTS}

A new transport system has a lot of impacts on several fields. This section reflects the impacts of the realization of CTS in urban areas. A scorecard is drawn to compare the performance of different means of urban transport on criteria that can be used to define sustainable mobility. Part of the criteria results 
from the sustainable indicators that are identified by Bryld [2]. The scorecard is shown in Table 1, based on Aben [1].

The result of the scorecard looks good for CTS. Based on this quantitative overview CTS could contribute to sustainable mobility. Furthermore it shows that the car scores very well on social indicators. The two conventional public transport modes perform averagely. A main advantage is that they are able to process a large amount of travelers at once. The table cannot be used to give firm judgments about the contribution to sustainability; it just gives an overview of the expected qualitative contribution. To make a better consideration of the sustainable contribution of CTS, further quantification is necessary as well as more information about the intended design of CTS.

Table 1: $\quad$ Effects of different motorized transport systems in urban areas [1].

\begin{tabular}{|c|c|c|c|c|c|}
\hline & Criteria & CTS & $\begin{array}{l}\mathrm{PT} \mathrm{P} \\
\text { rail } \mathrm{r}\end{array}$ & $\begin{array}{l}\mathrm{PT} \\
\text { roa }\end{array}$ & $\begin{array}{l}\text { Car } / \\
\text { motor }\end{array}$ \\
\hline \multirow{5}{*}{$\begin{array}{l}\text { Economica } \\
\text { indicators }\end{array}$} & capital goods & ++ & ++ & + & + \\
\hline & used fossil fuel energy reserves & -- & - & - & -- \\
\hline & environmentally sound capital goods & + & + & - & - \\
\hline & accessibility & + & +0 & 0 & - \\
\hline & impact on infrastructure & ++ & +++ & + & + \\
\hline \multirow{7}{*}{$\begin{array}{l}\text { Environ- } \\
\text { mental } \\
\text { indicators }\end{array}$} & emissions greenhouse gasses $\left(\mathrm{CO}_{2}, \mathrm{CH}_{4}, \mathrm{~N}_{2} \mathrm{Og} / \mathrm{pkm}\right)$ & 0,03 & 0,89 & & 1,3 \\
\hline & emissions of sulfur oxides $\left(\mathrm{SO}_{\mathrm{x}} * 10^{-6} \mathrm{~g} / \mathrm{pkm}\right)$ & $?$ & 3 & & 5,9 \\
\hline & emissions of nitrogen oxides $\left(\mathrm{NO}_{\mathrm{x}} \mathrm{g} / \mathrm{pkm}\right)$ & 0,25 & 1,12 & & 0,65 \\
\hline & ambient concentrations pollutants in urban areas & - & -+ & + & ++ \\
\hline & overall results on emissions & -- & --+ & + & ++ \\
\hline & congestion & - & -0 & 0 & + \\
\hline & noise nuisance & - & +0 & 0 & 0 \\
\hline \multirow{6}{*}{$\begin{array}{l}\text { Social } \\
\text { indicators }\end{array}$} & time preliminary and after transport & - & 0 & 0 & $--*$ \\
\hline & frequency of service & + & $0 \quad 0$ & 0 & ++ \\
\hline & total waiting time trip & - & $0 \quad 0$ & 0 & -- \\
\hline & number of modal shifts & ++ & $+\quad+$ & + & $--*$ \\
\hline & infrastructure expenditure per capita & ++ & + & - & + \\
\hline & length of trips & -- & - & - & $++*$ \\
\hline
\end{tabular}

*depends on availability of parking space and possibility to drive door-to-door.

is better than

is better than

\section{The development of CTS}

The development of CTS takes place in several European research projects. These projects focus on the technical possibilities and system functionalities. The development of CTS has several advantages and disadvantages. An operational 
advantage is the decrease of labor costs, as the cybercar needs no driver anymore. Automated systems will become more reliable as the experience with these systems increases. This will lower the costs as well. This advantage allows the frequency of a service by CTS to be adjusted to the demand, and makes it possible to provide (semi-) individual transport if the capacity of the infrastructure is sufficient. It is expected that CTS can deliver a profitable service in ten years. A disadvantage of the development of CTS is the complexity of its realization, as dedicated infrastructure is necessary due to the inability of CTS to mingle with other traffic. Realizing infrastructure can be a problem, since the construction of infrastructure is expensive, the success of the system uncertain and the space available in urban areas scarce. The costs of the development of CTS can be higher than calculated due to the uncertain risks and the fact that systems have not yet proven themselves in a professional environment. Finally, the use of CTS results in an extra transfer. This can be a drawback in the usage of the system. It depends, however, on the willingness of the traveler to transfer.

It is expected that CTS can contribute to sustainable mobility; especially in relation to emissions, because cybercars are electric vehicles. Next to this, shorter waiting times and an on-demand service with little detour can deliver an acceptable social performance. Although the car still scores very high on social indicators, the innovative character of CTS can realize an economic impetus.

\section{Service possibilities for CTS}

This section provides analyses in order to show for whom and for what traffic flows a service by CTS can be designed. An overview can be found in Table 4. It is explained in this section, but first an analysis is made of services by CTS.

\subsection{A service by CTS}

It appears that CTS can perform a service in areas where the activity level is high and where travelers arrive spread in space and/or time, which means that there is a constant demand for traffic, but that there are hardly any high peaks. This is based on a survey conducted among potential CTS users. Services by CTS can be divided into individual and collective possibilities. The choices for these services are based on the demand characteristics that can be met by the characteristics of the service. This is shown in Table 2 [3].

\subsection{Traffic flows}

CTS is suitable for four types of traffic flows in urban areas. These traffic flows consist of people with a different motive to travel: the 'trip purpose' in Table 4.

Inner traffic consists of traffic with every possible motive. Suburban - center linkage traffic is only undertaken for working, shopping and leisure activities. Residential area collection and distribution is undertaken for commuter traffic, for shopping, paying visits, recreation and for taking away and picking up. 
Table 2: Likely CTS application according to demand and supply characteristics.

\begin{tabular}{|c|c|c|c|c|c|c|}
\hline \multirow{2}{*}{$\begin{array}{l}\text { Supply } \\
\text { characteristics } \\
\text { Demand } \\
\text { characteristics }\end{array}$} & \multicolumn{3}{|c|}{ Individual } & \multicolumn{3}{|c|}{ Collective } \\
\hline & 1 & 2 & 3 & 1 & 2 & 3 \\
\hline $\begin{array}{l}\text { Spreading in } \\
\text { space }\end{array}$ & yes & yes & no & yes & yes & no \\
\hline $\begin{array}{l}\text { Spreading in } \\
\text { time }\end{array}$ & yes & yes & yes & no & no & yes \\
\hline Activity density & high & high & high & high & high & high \\
\hline Car use & yes & no & yes & yes & no & no \\
\hline $\begin{array}{l}\text { Parking } \\
\text { problems }\end{array}$ & yes & no & yes & yes & no & no \\
\hline Network design & \begin{tabular}{|l|} 
few to \\
many
\end{tabular} & $\begin{array}{l}\text { many to } \\
\text { many }\end{array}$ & $\begin{array}{l}\text { few to } \\
\text { few }\end{array}$ & \begin{tabular}{|l|} 
few to \\
many
\end{tabular} & $\begin{array}{l}\text { few to } \\
\text { many }\end{array}$ & few to few \\
\hline Possible sites & $\begin{array}{l}\text { central } \\
\text { car park } \\
\text { to busi- } \\
\text { ness park }\end{array}$ & $\begin{array}{l}\text { holiday } \\
\text { park }\end{array}$ & $\begin{array}{l}\text { central } \\
\text { car park } \\
\text { to city } \\
\text { center }\end{array}$ & $\begin{array}{l}\text { central } \\
\text { car park } \\
\text { to centr. } \\
\text { business } \\
\text { district }\end{array}$ & $\begin{array}{l}\text { station to } \\
\text { university }\end{array}$ & $\begin{array}{l}\text { airport } \\
\text { station to } \\
\text { departure } \\
\text { terminal }\end{array}$ \\
\hline
\end{tabular}

Table 3: $\quad$ CTS suitable traffic flows in urban areas.

(n)


458 Urban Transport XII: Urban Transport and the Environment in the 21st Century

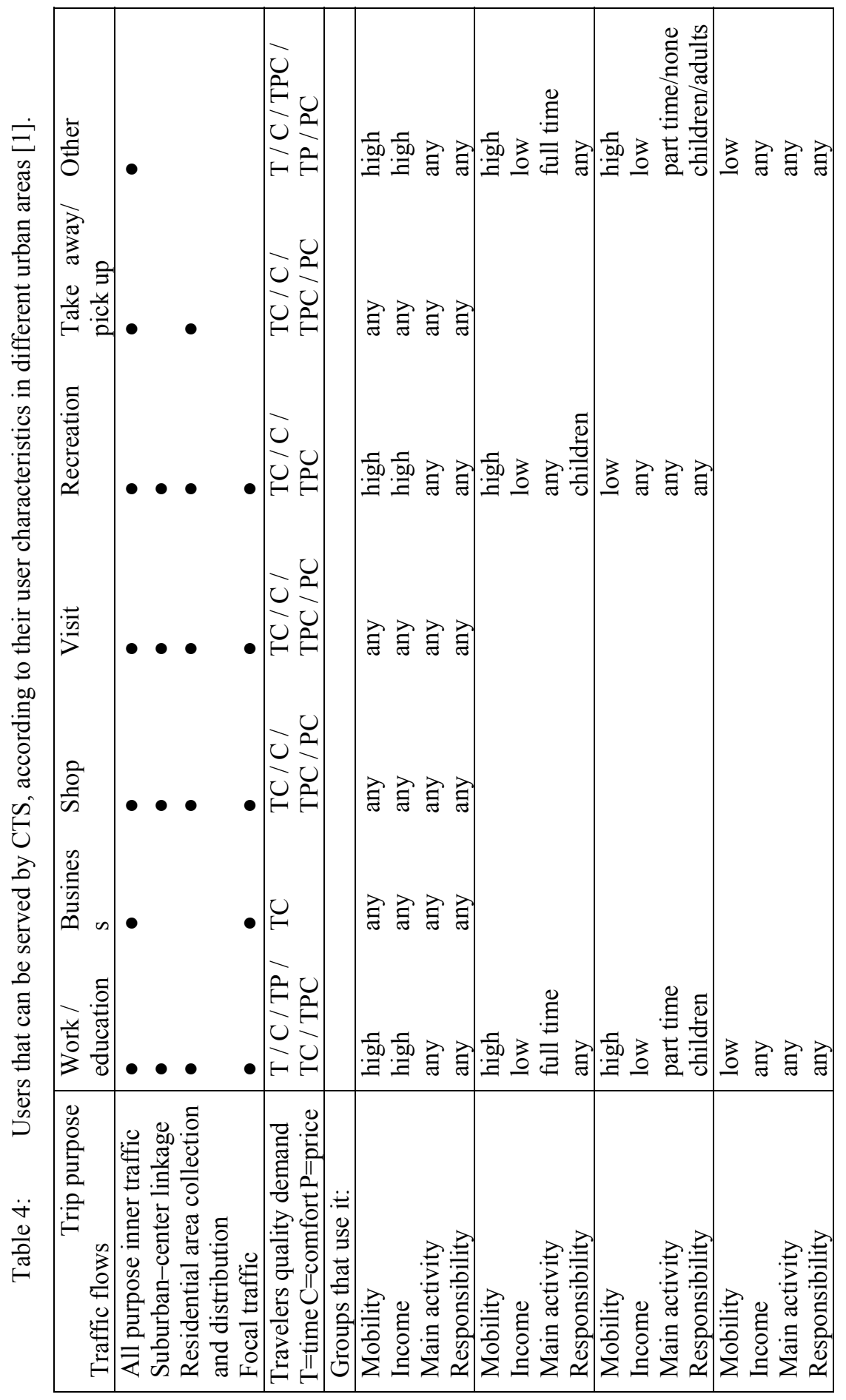

WIT Transactions on The Built Environment, Vol 89, (C) 2006 WIT Press www.witpress.com, ISSN 1743-3509 (on-line) 
Finally, focal traffic is undertaken for working, business, shopping, visiting and recreation. See Table 3 .

Most of the trips that can (partly) be executed by CTS are performed by inner traffic. A lot of different kinds of trips are also executed by residential area collection and distribution traffic and by focal traffic. When CTS is aimed at focal traffic, it should focus on part of a trip only, e.g. from a large parking lot to a center. Suburban - center linkages are least suitable for CTS. This can be improved when it is combined with focal traffic that enters the city through the suburbs. The identified flows need to be made up of travelers that have at least commuting or shopping as their trip purposes, to make sure that the service offered can be used efficiently.

\subsection{Traveler groups which can be served}

Table 4 gives an overview of trip purposes for which CTS can be suitable and also gives an overview of which group of travelers can use CTS for what specific trip purposes. It makes clear which groups of travelers can be served in which area for which purpose. Dependent on their trip purpose travelers have different quality demands. Van Goeverden et al. [5] distinguishes quality demands in three groups: price, time and comfort.

It is assumed that people who only think price is important, will not use CTS, since it is uncertain how CTS will compete on price with other transport modes. It is expected that CTS will be cheaper than conventional transport, because of its operational advantages. However, a lot of practice and research need to be done before CTS indeed will be cheaper. Probably the performance is more expensive at the moment. Therefore it is assumed that only people who find time, comfort, time + comfort, time + price, comfort + price or time + price + comfort important will use CTS. When people think time is important and they travel by car, the use of CTS can only be worth considering when they are made to choose between different means of transport. This happens for example when there is a problem in reaching a destination by car. When people find time important and they travel by public transport, switching is probably easier, because they are used to public transport services. When people find comfort important and they travel by car, CTS can be a consideration, as individual transport is possible when the transport flows are not too substantial. However, it does not seem obvious that people will switch from car to CTS only for the sake of comfort. When people find comfort important and they travel by public transport, CTS could be worth considering, since the service can be more direct and sometimes individual. When people find time and comfort important and they travel by car, CTS could be considered a good alternative. These travelers do not lose a lot of comfort and they can even gain time, especially when there is a problem in reaching their destination by car. When people find time+comfort important and they travel by public transport, CTS could be a good alternative. The advantages mentioned for people who find time+comfort important also hold for people who only find time and for people who only find comfort important. For people who find price important in combination with time and/or comfort, CTS can be an alternative as well. CTS can also be an alternative for people traveling by car, 
because they can save parking money in the city center in case CTS is used as a park shuttle. For people who use public transport it can be an alternative, because the service being offered by CTS is better than the service offered by conventional transport. This service would be far more expensive when it is offered by conventional transport, take e.g. the price of current taxi services, where even "drive up" costs have to be paid. These vary between 0 Euro and 5,12 Euros.

According to Van Goeverden et al. [5] when time is important, all modes are used to get into the city and also for traveling within the city. When costs are important, only slow traffic on short distance is attractive. When comfort is important, the car and public transport are dominant modes on trips in the city and over longer distances. The car is dominant on short trips outside the city.

Finally, based on Table 4 can be determined which trip purposes occur in an urban zone and which travelers are likely to use CTS based on their demand characteristics. This is only based on theories and analyses about traffic flows and travelers causing these traffic flows.

\section{The development of automated transport systems}

Next to the operational development of CTS, the development track of a transport system is, in general, also important to gain insight into the expectations for the future. At the moment CTS is in its pioneering stage, which is characterized by: lack of standardization, realizing many pilot projects, the development of comparable systems and the spread of knowledge. Several features are important for CTS to make it to the stage of rapid growth. Firstly, the technology needs to be geared to user demands. This is possible when the user demands are taken into account in the current development of CTS and in the executed pilot projects. Secondly, the growth of the system can increase when the available infrastructure can be used. To make this happen infrastructure should be made available for CTS. It is hard to make infrastructure available in dense urban areas. Solutions are available, for example the use of available, connecting pieces of infrastructure not yet used for conventional traffic. Thirdly, the standard production process of cybercars and the operational services need to be developed, in order to make the system available for a larger group of users. CTS should be developed more often to be able to design a standard. So far, no standardization has taken place in the development of cybercars because possible services need to be adjusted to the wishes of the operator and the user. The step of CTS to the next stage is not impossible but, until now, very uncertain.

The development of new transport systems can be seen as a transition [4]. This is a change in which the direction is clear but the final destination is not. At the moment several governments try to steer a transition to sustainable mobility. The role of the municipality in the development of sustainable mobility appears late in the process, due to its dependencies on financial resources and legislation. However, the municipality is very important in the development towards sustainable mobility: the negative effects of traffic are clearly visible in urban areas. This causes the municipality to be one of the problem owners, which increases and strengthens its role in the process. 


\section{Dutch municipalities' role in the CTS development process}

Dutch municipalities have no decision power anymore in the development and design of public transport in their areas. Now regional authorities are responsible for the development of public transport in urban areas and in spatial planning. Governors of a municipality participate in the daily board of the regional government and can therefore decide about the decisions in this field.

Municipalities often play a prominent part in the development of CTS. They can be initiator of a project to develop new transport systems. There are several motives to initiate a project. A problem perception is very important. Next to this the improvement of the image of the city can play an important second role in this initiative. Sustainable mobility is rarely a motive to realize automated transport. Due to its problem perception and with this the commitment to a project, a municipality can also play the role of process manager, facilitator and designer of the agenda. Having knowledge of and having good experiences with a system is very important for a municipality to gain trust and insight into the possibilities of the system. Next to this, the public support for the development is important. An influential governor, for example an alderman, can fulfill an important role to create public support. A region needs to grant tenders for public transport. For financial resources it depends on higher governments. The economical feasibility of a tender is important to grant a concession to an operator. Since the risks for CTS are rather high and the system has not proven itself professionally, the economical feasibility is uncertain. Due to these reasons, the regions in the Netherlands are hardly initiators of the development of new transport systems.

New systems will, because of the financial consideration, probably not be realized on a large scale with a standard tender procedure. Financial resources for the development can be found in project programs of governments in funds and in subsidies. These resources are often bond to specific demands, making the search for appropriate resources more difficult.

\section{Conditions for success in the development of CTS}

Several features being important for the development of CTS can be identified. These can be split into organizational, technical and a combination of these features. A problem perception with CTS as part of the solution is essential for the success of a project. Furthermore, combining technical and organizational possibilities is required to make a suitable design for CTS to contribute to the current situation. Moreover, the commitment of parties to the project, regardless of the length and the complexity of the process is necessary to gain success.

\section{Conclusions and discussion}

CTS are able to perform a service that can deliver a contribution to the services of the current transport system. This service is not bound to niches. With the introduction of CTS, the whole lay-out of the transport system can be revised to make a more efficient design. This design will be based on the functionalities of 
available transport systems, conventional as well as automated ones. In the long term the service network for CTS can be expanded. This depends on the choices that are made along the development process of CTS. In the short term, CTS has to prove itself in a professional application. This brings along uncertainties that decrease the chances for success. The development of new transport systems needs to be stimulated. Possibilities need to be initiated to free financial resources for further development of CTS. Next to this the financial resources should be less bond to specific demands.

Municipalities fulfill an important role in the development of CTS. CTS will not be realized in urban areas without municipal initiatives and their commitment to the process. However, a municipality is too dependent to be able to realize a system on its own. It often seems that the choice for a municipality for a new system is technology driven. This is due to the fact that knowledge about a new transport system is gained accidentally by having contact with a supplier or developer of these systems. An extensive decision support system should be designed to focus the consideration for the use of a system on its functionalities. Such a decision support system can combine the content of the development (systems and their functionalities) with the possibilities to design a process. The identified conditions for success can be used to fill this system, if they are specified. Furthermore, gaining information of cooperative projects in which many participants of different disciplines are involved can create insight into the process of the development. The decision support system can be designed by a knowledge institute and can be made available by knowledge platforms.

A project will never succeed when not being made use of by travelers. Further development of CTS should therefore be aimed at serving the traveler. The performed analysis can be used to find traveler groups and traffic flows for which CTS can be suitable. The defined conditions for failure or success of a project are no guarantee for success. Each development knows its own environment and parties involved. Therefore it is not possible to design an action plan for a successful realization of CTS. The conditions are useful in the development of CTS, since they can prevent pitfalls and make sure that chances are taken.

\section{References}

[1] Aben, E., Automated transport in urban areas, TNO/TU Delft: Delft, 2005.

[2] Bryld, B., CSD Working list of indicators of sustainable development. Sustainability indicators: report of the project on indicators of sustainable development, ed. B. Moldan \& S. Billharz, John Wiley \& Sons: Chichester, 1997.

[3] Eijkelenberg, P. \& Janse, M.M., From technology driven inventions to transport demand innovations, TNO Inro: Delft, 2003.

[4] Filarski, R., The rise and decline of transport systems: changes in a historical context. AVV, Ministry of Transport and Public Works, Rotterdam, 2004.

[5] Goeverden, C.D. van, Egeter, B. \& Hilbers, H.D., Staalkaart vervoersvraag, TU Delft: Delft, 1998.

[6] McDonald, M. \& Vöge, T., User needs analysis and analysis of key technologies, D1 Part 1 Report on user needs for CTS, TRG: Southampton, 2000. 